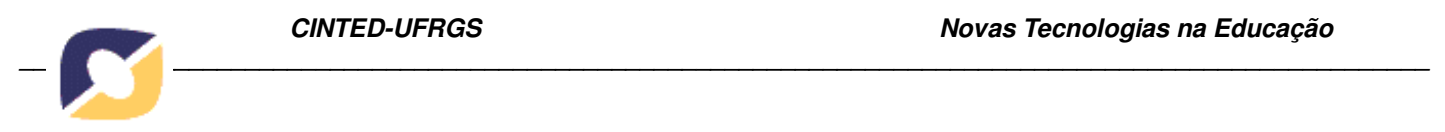

\title{
ETC: o que mudou e por quê? ${ }^{1}$
}

\author{
Alexandra Lorandi Macedo - UFRGS - alorandimacedo@ gmail.com \\ Cláudia Zank - UFRGS - claudiazank@gmail.com \\ Filipe Vinade - UFRGS - xvinadex2@hotmail.com \\ Patricia Alejandra Behar - UFRGS - pbehar@terra.com.br
}

\begin{abstract}
Resumo: A análise de textos produzidos no Editor de Texto Coletivo (ETC) e de depoimentos e avaliações de alunos e professores sobre o uso, as potencialidades e limitações do ETC apontaram indicadores sobre a necessidade de aprimoramento do sistema. Este artigo discorre, assim, sobre os aspectos que levaram à reconstrução e aperfeiçoamento do Editor, destacando os ajustes realizados e a tecnologia que permitiu tal reestruturação. Por fim, contempla dados coletados em estudos de casos com o fim de validar as alterações realizadas no ETC.
\end{abstract}

Palavras-chaves: Editor de texto coletivo, ferramentas de interação e interface.

Abstract: The analysis of texts produced in the Editor of Collective Text (ETC), along with assesments and evaluations by students and teachers on the use, capabilities and limitations of the ETC, indicated a need for an improvement of the system. This article therefore examines the issues that led to the reconstruction and improvement of the Editor, highlighting the adjustments made and the technology that allowed such restructuring to be achieved. Additonally, the article looks at data collected from case studies in order to validate the alterations made in the ETC.

Keywords: Editor of Collective Text, interaction tools and interface.

\section{Introdução}

Este artigo tem por objetivo apresentar a reestruturação realizada no Editor de Texto Coletivo (ETC), a partir de avaliações feitas com os usuários em contextos educacionais. O ETC ${ }^{3}$ é um editor de texto on-line, construído em 2001 pelo Núcleo de Tecnologia Digital aplicada à Educação da Universidade Federal do Rio Grande do Sul (NUTED/UFRGS). Esse foi desenvolvido para fins educacionais, mas não se restringe a esse público. O editor encontra-se disponível na web e sua utilização é livre para todo aquele que tiver interesse em produzir textos coletivamente. O ETC vem sendo aprimorado a partir de depoimentos e avaliações de professores e alunos usuários do sistema. Alguns dos principais ajustes e inovações implementadas ao longo desses anos são detalhados em Behar et al. (2005; 2006; 2007 e 2009).

Destaca-se que a presente reestruturação está sendo considerada pelos desenvolvedores como a mais robusta, por levar em conta o nível de permissões de administração de usuários, forma de edição de texto e o design da interface gráfica.

Entende-se que fomentar e manter o interesse na busca do permanente aprimoramento do sistema é uma forma de valorizar toda a comunidade de usuários, pois sempre lhes proporciona melhores condições para o desenvolvimento de suas práticas. Nesse sentido, este estudo descreve os motivos que levaram a equipe a desenvolver a nova versão do Editor. Além disso, aponta os elementos incorporados, apresenta dados de sujeitos que utilizaram esta nova versão e, por fim, aponta as primeiras conclusões desse processo. 


\section{Por que mudou e o que mudou?}

O ETC se constitui em um editor de texto coletivo, o qual foi desenvolvido pelo NUTED/ UFRGS com o objetivo de propiciar a escrita coletiva através da Web. A necessidade de sua construção surgiu a partir das dificuldades observadas na elaboração de trabalhos coletivos, mais precisamente nos cursos à distância, por meio da rede.

Assim, o ETC se configura como um ambiente de trabalho coletivo cooperativo/colaborativo. O usuário constrói seu conhecimento na interação com os outros participantes, com os recursos e funcionalidades do ambiente, materiais publicados, produções dos demais usuários e os seus próprios registros. Para tanto, o ambiente oferece condições de trocas entre os participantes por meio de ferramentas destinadas à interação entre os sujeitos envolvidos (ZANK et al., 2008).

As ferramentas consideradas de apoio são, portanto, aquelas que promovem a interação/comunicação entre os usuários e proporcionam o armazenamento e consulta de conteúdos relacionados. Existe ainda o espaço de trabalho, ou seja, a edição de texto, que conta com funcionalidades de formatação e edição.

Desde sua criação, o Editor vem sendo utilizado em disciplinas de graduação e pósgraduação e em cursos de extensão da UFRGS, tanto na forma semi-presencial quanto a distância. A partir dos depoimentos e avaliações de professores e alunos usuários são levantados indicadores que permitem aprimorar o Editor. Dados analisados, especificamente entre 2008/2 e $2009 / 1^{2}$, mostraram que os usuários tinham dificuldade em administrar a edição de texto. Nesse sentido, não consideravam o ETC uma ferramenta amigável e, por essa razão, procuravam realizar a construção coletiva em outros editores, como o Word, por exemplo.

O cenário identificado motivou o início de uma reestruturação do ETC. Esta ocorreu nos seguintes aspectos: administração de dados e cadastros, que nesta versão dá liberdade de criação, edição e gerenciamento igual para todos os participantes; na forma de edição de texto, onde pode ser editado o conteúdo por completo e de forma simultânea entre os usuários; e, por fim, na reformulação integral da interface ${ }^{4}$.

A Tabela 1 apresenta, de forma objetiva, os itens reestruturados no ETC. Detalhes sobre cada uma das alterações seguem nos subitens desta seção. 


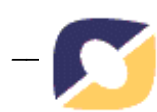

Tabela 1 - O que mudou no Editor de Texto Coletivo

\begin{tabular}{|l|l|}
\hline \multicolumn{1}{|c|}{ ETC - Versão anterior } & \multicolumn{1}{c|}{ ETC - Versão atual } \\
\hline $\begin{array}{l}\text { Acesso de novos usuários ocorria mediante } \\
\text { aprovação do administrador. }\end{array}$ & $\begin{array}{l}\text { Não existe mais um administrador. O usuário } \\
\text { preenche um formulário de cadastro e já pode } \\
\text { utilizar o Editor. }\end{array}$ \\
\hline $\begin{array}{l}\text { As ações eram centradas no usuário que } \\
\text { criava o grupo e os textos, geralmente o } \\
\text { professor. }\end{array}$ & $\begin{array}{l}\text { Todo usuário do ETC pode criar seus textos e } \\
\text { convidar outros usuários para participar do } \\
\text { mesmo. }\end{array}$ \\
\hline O texto era editado por parágrafos. & $\begin{array}{l}\text { O conteúdo é editado como um todo e de } \\
\text { forma simultânea. }\end{array}$ \\
\hline $\begin{array}{l}\text { Para trocar ideias sobre o texto os alunos } \\
\text { utilizavam a Ferramenta Comentários } e \\
\text { Fórum. }\end{array}$ & $\begin{array}{l}\text { Além da Ferramenta Comentários, foi } \\
\text { desenvolvida uma ferramenta de comunicação } \\
\text { síncrona, o Comunicador, para que os alunos } \\
\text { possam conversar online sobre o texto. }\end{array}$ \\
\hline $\begin{array}{l}\text { Não era possível enviar mensagem para os } e- \\
\text { mails dos participantes. }\end{array}$ & $\begin{array}{l}\text { A Ferramentas Mensagem foi incluída e } \\
\text { permite que se envie mensagens para os } e- \\
\text { mails dos participantes. }\end{array}$ \\
\hline
\end{tabular}

\subsection{Cadastro de usuário, grupos e textos}

Até o presente momento, o ETC só permitia o acesso de novos usuários mediante aprovação do administrador. Para isso, o interessado preenchia um formulário online, disponibilizado na página inicial do sistema, informando dados de identificação e uma breve justificativa do interesse em utilizá-lo. Na nova versão, o usuário deve preencher um formulário de cadastro para iniciar o uso do Editor. Entende-se que essa prática oferece maior liberdade, abrangência de público e agilidade no acesso de inúmeros internautas ao ETC. Esse é um dos grandes interesses da equipe desenvolvedora. O NUTED, que fomenta a pesquisa e o desenvolvimento, tem como uma de suas metas oferecer para uso da comunidade os produtos desenvolvidos. Logo, entende-se que este objetivo pode ser favorecido a partir do novo princípio de cadastro.

$\mathrm{Na}$ versão anterior, como se tinha por referência o professor como articulador de uma turma de alunos, o sistema exigia a criação de grupos e, dentro destes, a criação de textos. A partir daí, os usuários já cadastrados eram alocados em suas respectivas produções. Porém, estas ações eram centradas no usuário que criava o grupo e os textos. $O$ perfil desse usuário lhe dava privilégios particulares, não estendendo a permissão aos demais. Esse tipo de cadastro também foi completamente reformulado. Pensando na liberdade de acesso de usuários interessados em produzir textos coletivos online, na atual versão, todo sujeito que faz seu cadastro no ETC, pode criar seus textos e convidar outros usuários para participar do mesmo, desde que estes também sejam cadastrados no sistema. Entende-se que esta nova permissão, abrangerá o acesso e utilização por diferentes grupos, não só os gerenciados por professores.

Sabe-se que, atualmente, são cada vez maiores as ofertas de sistemas que favorecem a produção de textos coletivos online, mas isso não intimida o grupo desenvolvedor do ETC. Isso porque os pesquisadores envolvidos entendem que existem diferentes perfis e contextos onde os editores são utilizados, e de onde são geradas inúmeras novas necessidades. Como os testes das pesquisas são feitos em contextos educacionais, entende-se que o sistema poderá oferecer melhores condições para aplicações educacionais, ainda que o Editor não se restrinja a esse público. Com a nova forma de cadastro de usuário, os grupos de alunos, de amigos, de internautas ou mesmo empresas que tenham interesse em produzir textos coletivos, poderão 


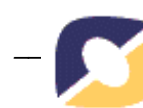

eleger o ETC para essa atividade.

\subsection{Forma de edição do texto e ferramentas de comunicação}

Outro forte elemento que dificultava o pleno uso do ETC era sua forma de edição de texto. Até o momento, o texto era editado por parágrafos. Cada usuário podia, ativando a edição, alterar, incluir ou excluir parágrafos de um texto. Isso fazia com que a produção textual não fluísse com facilidade, pois cada trecho era editado em uma janela separada do texto como um todo. Desta forma, criava-se um ambiente que favorecia uma justaposição de parágrafos, dificultando a fluidez e coerência da produção. Para sanar essa dificuldade, o modo de edição foi alterado. Na nova versão, o conteúdo é editado como um todo. Basta clicar na página e iniciar a escrita. Vale destacar que, a partir desta nova versão, o texto pode ser escrito por diferentes usuários de forma simultânea. Além disso, o editor gera um endereço eletrônico para que a produção possa ser visualizada, a partir de um navegador web, por qualquer usuário, independente de ele ser cadastrado no ETC.

Desde a sua criação, o ETC tem como base teórica a piagetiana, na qual o foco está na interação entre os sujeitos, sob o ponto de vista das trocas sociais (Piaget, 1973). Com base nessa perspectiva, o Editor sempre contou com recursos que favorecessem a troca de ideias entre os participantes. Na versão anterior, estava disponível, em cada parágrafo, a ferramenta "Comentários" que servia para os usuários deixarem recados uns para os outros ou para fazerem observações sobre a escrita. Na versão atual, além da ferramenta "Comentários", está disponível a ferramenta "Comunicador". Ela exibe usuários que estão online, permitindo que conversem em tempo real. Além destas, o ETC oferece as ferramentas "Fórum" e "Mensagem". O "Fórum" pode suportar discussões teóricas sobre a produção textual ou suportar a discussão sobre os diferentes pontos de vista entre os participantes. Já a ferramenta "Mensagem", desenvolvida para essa nova versão, permite que os usuários enviem e-mails uns para os outros.

\subsection{Estrutura da interface}

Por fim, tem-se a reconstrução da interface que se fez necessária pela robusta reconstrução feita no Editor. Para essa reconstrução, foram tomados como base dois diferentes enfoques: a capacidade de aprendizagem (learnability) e a capacidade de memorização (memorability). Entende-se a capacidade de aprendizagem como o tempo que se leva para conseguir iniciar a utilização do sistema e para aprender a realizar um conjunto mais amplo de tarefas. Já a capacidade de memorização é relacionada ao tipo de suporte que foi fornecido para que o usuário possa lembrar como se dá a sua utilização, especialmente para as operações que não são usadas com frequência (Preece et al., 2005). Ao levar em consideração estes dois enfoques, tem-se a intenção de proporcionar um ambiente que propicie a interação e o trabalho em grupo, que seja agradável e esteticamente apreciável e que também incentive a criatividade.

Tomando por base o design de interação, buscou-se ofertar condições favoráveis ao usuário, de modo que seus objetivos no ambiente sejam alcançados. Assim, foram definidas metas de usabilidade, que dão conta de ressaltar os principais pontos a serem observados no desenvolvimento de um sistema. Dentre estas metas de usabilidade encontram-se a eficácia do sistema, que se refere ao seu êxito na execução das tarefas a que se propõe; e a eficiência, que tem relação com a maneira como o sistema auxilia o usuário na realização das tarefas, se propicia produtividade. Assim, a usabilidade implica em otimizar a relação entre pessoas e produtos interativos. No caso do ETC, o design de interação tem como objetivo principal promover o bom desempenho do usuário frente ao sistema. $\mathrm{O}$ bom desempenho deve acontecer desde o primeiro contato com o Editor, criando condições para que as próximas vezes em que 


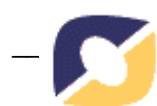

acessar o documento, seja fácil de lembrar a navegar no sistema, dispensando nova adaptação (Behar et al., 2009).

A seguir, a Figura 1 apresenta a atual tela de edição de texto.

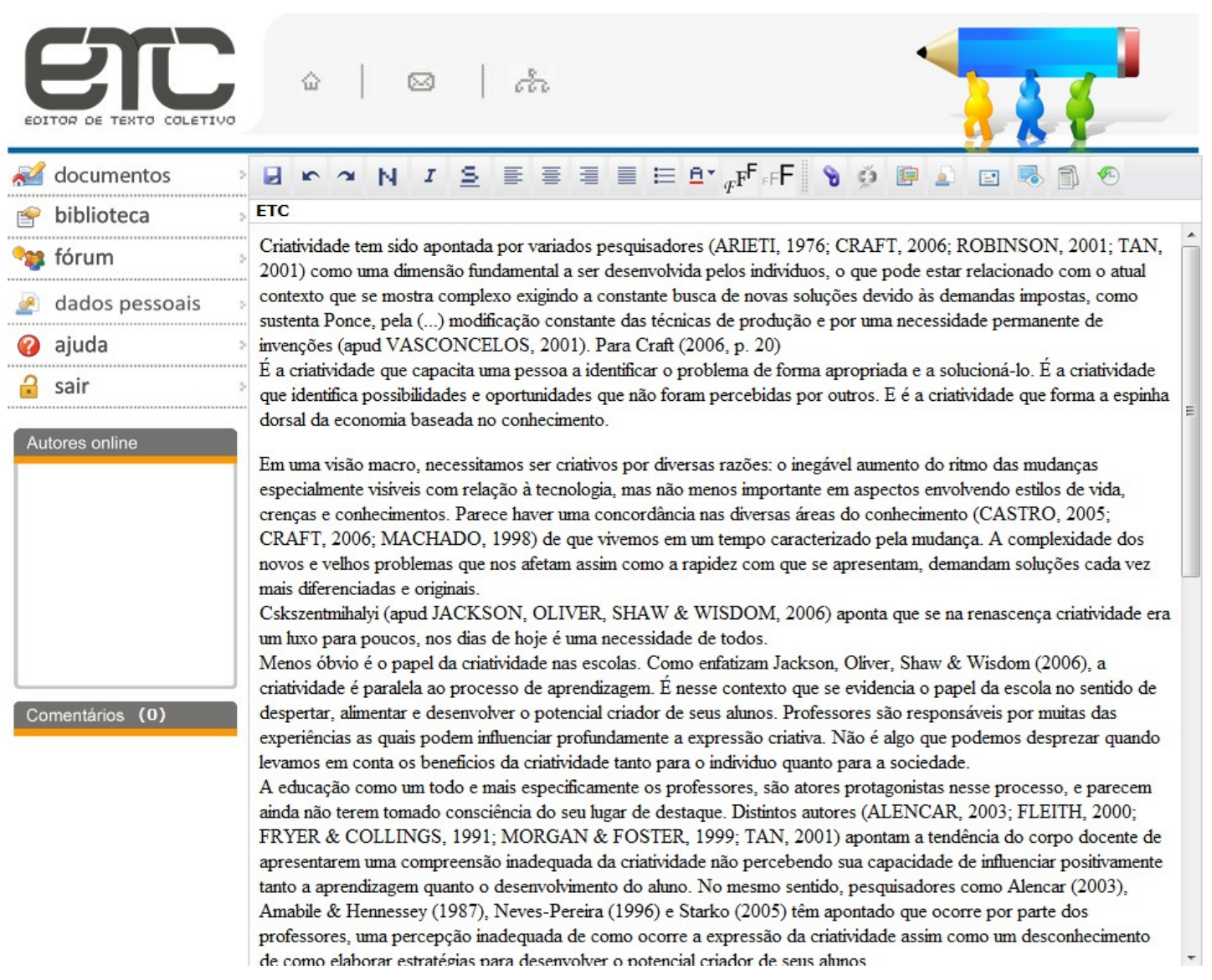

Figura 1 - Tela atual de edição de texto

\section{Princípios técnicos que viabilizaram a reestruturação do ETC}

Para viabilizar todas as alterações feitas na atual versão do Editor, foi necessário buscar recursos tecnológicos que atendessem às demandas. Assim, destaca-se que o desenvolvimento do ambiente foi dividido em duas áreas: a do projeto com foco no servidor e a área do projeto com foco no usuário. No desenvolvimento para o servidor, continuou-se utilizando o SGBD MySQL e a linguagem de programação PHP. No desenvolvimento para o usuário trabalhou-se com HTML, CSS e JavaScript, além de AJAX e o framework jQuery. As tecnologias utilizadas em ambas as áreas não possuem custo de licença e apresentam grande disponibilidade de material para consulta na internet.

Logo, se na primeira versão do ETC foi implementada a programação cross-browser ${ }^{5}$, a qual possui como desvantagem um aumento substancial no tempo de programação, já na nova versão foi feita a inclusão do framework jQuery, que, por ser compatível com a maioria dos browsers, diminui o esforço de adaptação do ambiente para diferentes browsers.

A escolha do AJAX se deu porque se trata de uma técnica de programação na qual é criada a comunicação com o servidor de forma assíncrona. Isto permite uma série de 


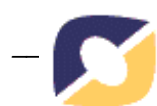

funcionalidades, entre estas: carregamento de imagens no texto sem o recarregamento de imagens da página; visualização de quem está online no texto; comunicação síncrona para troca de mensagens; entre outras.

O uso do jQuery permitiu, por fim, simplificar o código e facilitar a aplicação de efeitos visuais. A partir dele, foi possível desenvolver a inclusão e a exclusão de botões da barra de ferramentas com a utilização da técnica drag-and-drop ${ }^{6}$.

Por fim, vale destacar que o ETC foi construído com seu código-fonte aberto ${ }^{7}$. Dessa forma qualquer pessoa, devidamente capacitada, pode modificá-lo e adaptá-lo de acordo com suas necessidades.

\section{Resultados preliminares}

A partir da reestruturação do Editor, em 2009/2 foi ministrado o Curso de Extensão intitulado "Desenvolvendo a Competência para o Trabalho em Equipe", o qual foi a primeira oportunidade de validação da nova versão do Editor de Texto Coletivo.

Assim, a partir dos dados coletados ${ }^{9}$ durante a realização deste curso, o presente artigo passa a analisar as ferramentas da nova versão do ETC. O intuito é verificar se as alterações ocorridas nos recursos já existentes e se as novas implementações estão alcançando o objetivo de facilitar e potencializar os processos de interação e se o espaço de trabalho tornou-se um espaço apropriado para que o usuário possa realizar suas tarefas.

\subsection{Ferramentas de comunicação}

Uma das ferramentas muito utilizadas pelos alunos na versão anterior do ETC era a ferramenta Comentários, tendo sido, por essa razão, mantida na nova versão. No curso de extensão realizado, observou-se, no entanto, que ela foi pouco utilizada. Nos extratos abaixo, os alunos ${ }^{10}$ dão as razões para o pouco uso da ferramenta:

(Ana): Eu coloquei ali [no "Comentários] uma vez, mas eu pensei assim: "Pô, então manda um e-mail". Eu achei que a pessoa não fosse ler, fosse esquecer porque fica ali no cantinho, no rodapé, de repente a pessoa nem vai lembrar de ler, de entrar ali.

(Aici): Ou sinalizar que "ô, você tem recadinho". Ou alguma coisa assim. Tem que marcar, sabe? Fazer um quadrinho. "Opa, entrou uma coisa nova". Clica lá. Não tem? Não entrou nada desde que tu leu.

Os alunos apontam como razões para o não uso da ferramenta a localização e a falta de sinalização de novos comentários. Como a reconstrução do ETC tem por objetivo seguir critérios de usabilidade, implicando em otimizar a relação entre os usuários e o ambiente, a equipe de desenvolvimento do ETC decidiu alterar a localização da ferramenta dentro da página de edição de texto.

Outra ferramenta assíncrona, "Mensagem", foi desenvolvida para esta versão do ETC com o objetivo de contribuir nos processos de colaboração/cooperação e comunicação/interação entre os participantes. No entanto, apenas um dos grupos a utilizou com maior frequência. A ferramenta foi, em geral, pouco utilizada. Uma das contribuições para melhoria nessa ferramenta é feita pelo sujeito Ana, que alerta sobre o fato de não poder escolher para quem enviar a mensagem: 


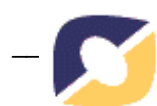

(Ana): Eu não usei, mas eu não gostei de uma coisa. Eu não queria mandar para todo mundo. De repente eu não soube usar. Mas eu não queria que tu [a professora] recebesse, queria que só o pessoal do grupo recebesse. [...] Eu não queria mandar para todo mundo, eu acabava usando e-mail mesmo. Porque eu não queria o grupo.

Entendendo que as ferramentas desenvolvidas para a nova versão do ETC deveriam oferecer condições favoráveis à realização das tarefas, também se buscou, posteriormente ao curso, fazer melhorias nas mesmas. Desse modo, ela agora possibilita aos usuários escolher a quem, dentro do texto ou da pasta, enviar mensagens.

Com relação à ferramenta síncrona Comunicador, esta tem por objetivo possibilitar aos usuários se comunicar durante a escrita coletiva para coordenarem suas ações e não acontecer de um salvar seu texto e, consequentemente, apagar do outro. Os alunos, no entanto, não conseguiram fazer esse uso da ferramenta, pois ela apresentou uma série de falhas, entre estas o não funcionamento em alguns navegadores; os nomes dos usuários online não apareciam; ou, ao contrário, os usuários saíam da tela de edição e seus nomes continuavam como online. O sujeito Aici relata algumas dessas falhas:

(Aici): Só aparece quando for no Mozila, no navegador do Mozila. Se for no Internet Explorer não aparecem as pessoas. [...] E hoje o meu é Internet Explorer. O meu não abria isso. Então eu entrava lá, não via ninguém..."Oba, posso digitar, salvar, que não vai dar problema", mas poderia ter dado. [...]

\subsection{Edição do texto}

A edição simultânea traz o risco de perder o que foi digitado se outro colega salvar durante a edição, por essa razão a importância da ferramenta anteriormente mencionada, o Comunicador. Como esta ferramenta apresentou falhas que impediram os alunos de conversarem durante o processo de escrita coletiva, a forma instantânea de editar, aliada às falhas no Comunicador, gerou medo nos participantes de perder o texto recém digitado:

(Aici): Eu acho perigoso essa coisa de tu tá aqui fazendo e aí tu salva. Teu colega também tá fazendo e salva. Essa coisa de salvar e que pode perder o trabalho, só isso que eu acho muito perigoso.

Este medo resultou no pouco uso da edição de texto. Nesse sentido, os alunos utilizaram outro editor para redigir e copiaram os textos no ETC. Entendendo, portanto, que estas falhas impedem a eficácia e a eficiência do ambiente, além de não possibilitar a construção do conhecimento por meio da escrita coletiva, buscou-se imediatamente sanar estas questões, devendo ser a ferramenta novamente validada em situação de aula.

\subsection{As trocas sociais}

Os dados coletados sugerem ainda que a ferramenta Fórum foi a mais utilizada pelos participantes para se comunicar e se articular para realizar a escrita coletiva. O Fórum aparece como local de encontro dos grupos ${ }^{11}$, como espaço de interação e aproximação, mas também e, principalmente, como espaço de questionamento e reflexão. Nesse sentido, é a ferramenta que possibilitou interação entre os sujeitos, aproximando-se da perspectiva teórica que sustenta o desenvolvimento do Editor. Exemplo disso está na fala dos alunos presentes no Grupo Focal: 

amizades.

(Aici): [O Fórum] Ajudou a desenvolver as idéias. Para a troca de idéias...Novas

(Zita): Ele articulou, na realidade, a construção dessa rede, acho que foi essa a grande ferramenta.

Pode-se dizer, portanto, que o Fórum foi, nesse momento, a ferramenta do ETC que possibilitou aos alunos refletir, questionar, debater e, portanto, construir conhecimento acerca das temáticas trabalhadas. Os trechos ${ }^{12}$ que seguem sugerem que as trocas nos tópicos possibilitaram aos sujeitos participar de um processo de aprendizagem cooperativa, no qual os sujeitos tornamse interdependentes e se conectam a partir de problemas, interesses e experiências, as quais podem compartilhar entre si (PALLOFF, PRATT, 2002,p. 141):

(Ale): A riqueza dos debates nos fóruns, as novas amizades $e$ o aprendizado surgido a partir dele seguirão comigo para sempre.

(Itel): Para nós foi maravilhoso, e rápido como a Ale colocou, com certeza o tempo é nosso inimigo quando as tarefas são prazerosas, fica aqui regsitrado meu agradecimento pelas aprendizagens e quão rica foram. Que tempestade de ideias, que qualidade de sujeitos...

(Ana): Vcs não imaginam como os depoimentos e questionamentos de todos foram importantes para meu crescimento pessoal e profissional. Essa trajetória me tornou mais reflexiva acerca dos meus "CHA's" (conhecimentos, habilidades e atitudes), o que tenho que desenvolver e o que de fato estou mobilizando para o meu sucesso.

A análise dos dados leva a crer que, ainda que exista um espaço de trabalho como a edição de texto, é preciso que todas as funcionalidades disponíveis para os alunos estejam funcionando corretamente para que este espaço seja utilizado em todo o seu potencial. Sugere também que oferecer condições favoráveis ao usuário pressupõe contínuas validações e posteriores alterações, tanto de design quanto de programação, para que os aspectos pedagógicos possam então ser valorizados.

\section{Conclusão}

Após a utilização do ETC em disciplinas de graduação, pós-graduação e cursos de extensão oferecidos pelo NUTED/UFRGS, foi observado que os alunos estavam utilizando outros editores e colando os textos no ETC. Ao investigar as razões, viu-se que o Editor não era considerado uma ferramenta amigável.

Tal cenário motivou sua reestruturação. A mesma se deu por meio de alterações quanto à administração de dados, cadastros e edição de texto, reformulação de antigas ferramentas e criação de novas, além da reformulação integral da interface para readequação do conjunto de alterações feitas. Para tal reestruturação foram tomadas como base a capacidade de aprendizagem e a capacidade de memorização, tendo sido definidas como metas de usabilidade a eficácia e a eficiência do sistema.

Durante a realização de curso de extensão, foram coletados dados com o fim de analisar as ferramentas da nova versão do ETC, verificando se as alterações estão alcançando o objetivo de facilitar e potencializar os processos de interação e se o espaço de trabalho proporciona ao usuário realizar suas tarefas. 
A análise dos dados mostrou que algumas falhas nas ferramentas fazem com que os alunos não utilizem os recursos de interação em todo o seu potencial. Além disso, os usuários continuam optando por outros editores de texto, porém, em paralelo, utilizam a ferramenta Fórum do ETC para apoiar as discussões acerca da produção textual. Os apontamentos identificados foram extremamente válidos para os ajustes iniciais do sistema, os quais já foram providenciados e estão sendo colocados para validação em novo curso de extensão. No momento, os dados coletados se encontram em fase de análise. A preocupação em rapidamente providenciar os ajustes e validá-los mostra o foco no usuário e a preocupação da equipe de desenvolvimento do ETC em sempre lhe proporcionar melhores condições para o desenvolvimento de suas práticas.

\section{Notas de Texto}

${ }^{1}$ Este trabalho vincula-se ao projeto de pesquisa "Trabalho em Equipe: uma competência para a laboralidade por meio do ETC" em desenvolvimento no PPGEDU/UFRGS com apoio do CNPq.

${ }^{2}$ Disponível em http://www.nuted.ufrgs.br/etc2.

${ }^{3}$ Detalhes em Macedo (2010).

${ }^{4}$ Resultados preliminares do processo de reestruturação foram detalhados em Behar et al. (2009) e Macedo et al. (2009).

${ }^{5}$ Estilo de programação em que o código funciona em qualquer browser em diferentes plataformas.

${ }^{6}$ Drag-And-Drop é o evento de arrastar e soltar componentes, propiciando a transferência de objetos de uma maneira mais simples.

${ }^{7}$ O código-fonte está disponível em: http://www.nuted.ufrgs.br/etc2/fonte.

${ }^{8}$ Este teve como objetivo proporcionar momentos de discussão e reflexão e ainda fornecer subsídios para que os participantes pudessem construir um texto coletivo no ETC. curso foi aberto à comunidade e formou-se um grupo bastante heterogêneo, composto por estudantes de nível técnico, graduação e pós-graduação. A modalidade foi semipresencial, com 02 aulas presenciais e 02 aulas a distância.

${ }^{9}$ Detalhes em (Zank, 2010).

${ }^{10}$ Os nomes dos sujeitos foram trocados a fim de preservar suas identidades.

${ }^{11}$ Alguns grupos criaram tópicos para se conversar a respeito de suas produções coletivas.

${ }^{12}$ Destaques dentro dos trechos foram feitos pela pesquisadora (Zank, 2010).

\section{Referências Bibliográficas}

BEHAR, Patricia, MACEDO, Alexandra Lorandi, BITENCOURT, Jossiane B. e MAZZOCATO, Silvia B. Um editor de escrita coletiva na Web. In: I Encontro Internacional de Educação a Distância: políticas públicas e novas possibilidades de se fazer EAD, 2005, Taquara. Anais I Encontro Internacional de Educação a Distância.

BEHAR, Patricia, MACEDO, Alexandra L., BITENCOURT, Jossiane B. e MAZZOCATO, Silvia B.. Escrita Coletiva: o potencial de um Groupware via Web. Revista Novas Tecnologias na Educação, CINTED/UFRGS. v.4 No.1. Julho2006.

BEHAR, Patricia, MACEDO, Alexandra L. e MAZZOCATO, Silvia B.. Tecnologias de Suporte ao Trabalho Coletivo: planejamento e aplicação de um objeto de aprendizagem. In: XVIII Simpósio Brasileiro de Informática na Educação, 2007, São Paulo. XVIII Simpósio Brasileiro de Informática na Educação. Porto Alegre : SBC - Sociedade Brasileira de Computação, p. 9099. 


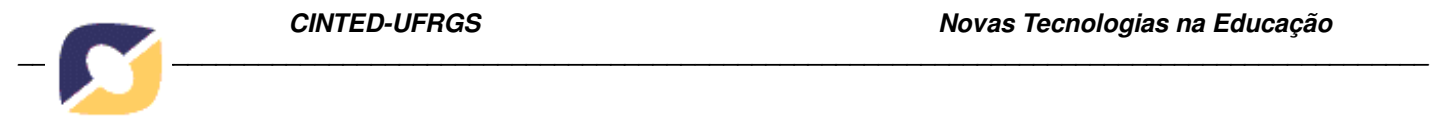

BEHAR, Patricia A.; MACEDO, Alexandra L.; PASSOS, Jaire. e.; PASSOS, Paula C. S. J.. Collective Text Editor: a new interface focused on interaction design. In: Arthur Tatnall; Anthony Jones. (Org.). Education and Technology for a better world. 1 ed. Berlin / Germany: Springer, v. 1, p. 331-339, 2009.

MACEDO, Alexandra L.; REATEGUI, Eliseo B. ; LORENZATTI, Alexandre; BEHAR, Patricia A.. Using Text-Mining to Support the Evaluation of Texts Produced Collaboratively. In: Arthur Tatnall; Anthony Jones. (Org.). Education and Technology for a better world. 1 ed. Berlin / Germany: Springer, v. 1, p. 368-377, 2009.

MACEDO, Alexandra Lorandi. Rede de Conceitos: uma ferramenta para contribuir com a prática pedagógica no acompanhamento da produção textual coletiva. Universidade Federal do Rio Grande do Sul, Programa de Pós-graduação em Informática na Educação, Porto Alegre, Brasil, 206p, 2010. Tese de Doutorado.

PALLOFF, Rena; PRATT, Keith. Construindo Comunidades de Aprendizagem no Ciberespaço. Porto Alegre: Artmed, 2002.

PIAGET, Jean. Estudos Sociológicos. Rio de Janeiro: Forense, 1973.

PREECE, Jeniffer; ROGERS, Yvonne; SHARP, Hellen. Design da interação: além da interação homem-computador. Porto Alegre: Bookman, 2005.

ZANK, Cláudia. Contribuições do Editor de Texto Coletivo (ETC) para o Desenvolvimento da Competência para o Trabalho em Equipe. Universidade Federal do Rio Grande do Sul, Programa de Pós-graduação em Educação, Porto Alegre, Brasil, 2010, 200p. Dissertação de Mestrado.

ZANK, Cláudia; TIELLET, Claudio Afonso B.; CUNHA, Claudio R.; LONGHI, Magalí Teresinha; SCHMITT, Marcelo R.; BEHAR, Patricia Alejandra. Construção de textos coletivos experiências através de um Groupware. In: V Congresso Brasileiro de Educação Superior a Distância (ESUD) e $6^{\circ}$ Seminário Nacional de Educação a Distância (SENAED). Gramado. São Paulo: ABED, 2008 